\title{
Palaeoclimate and palaeoseismic events discovered in Diexi barrier lake on the Minjiang River, China
}

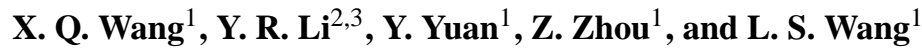 \\ ${ }^{1}$ State Key Laboratory of Geohazard Prevention and Geoenvironment Protection (Chengdu University of Technology), \\ Chengdu 610059, China \\ ${ }^{2}$ Taiyuan University of Technology, Taiyuan 030024, China \\ ${ }^{3}$ AGECON Ltd., Hong Kong, China \\ Correspondence to: Y. R. Li (li.dennis@ hotmail.com)
}

Received: 16 February 2014 - Revised: - Accepted: 10 March 2014 - Published: 14 August 2014

\begin{abstract}
Studies on the formation of the ancient Diexi barrier lake on the Mingjiang River, southwestern China, have long been carried out. However, investigations into the correlation between the palaeoclimate and palaeoenvironment and the palaeoseismic events in this area are rarely found in literature. The present study took sediments from the ancient Diexi barrier lake to investigate the palaeoclimate, palaeoenvironment and palaeoseismic events. A drilling at the centre of the barrier lake was conducted and the core of about $260 \mathrm{~m}$ long was examined. The palaeoclimate and palaeoenvironment indicators (sporopollen, carbon and oxygen isotopes, organic matter, calcium carbonate, granularity) from the sediments have been tested and analysed, and indicate that there were 10 climatic and environmental periods between 30000 and $15000 \mathrm{a} \mathrm{BP}$ (before present). The discovered disturbance segments in the core indicate there were at least 10 seismic events during that period. The consistency between climate change and seismic events indicates that a strong seismicity is normally accompanied by a climatic variation. This may be a useful supplement for climate and geohazard predictions in the future.
\end{abstract}

\section{Introduction}

The foreign matter caused by rockfall, landslide, debris flow and lava flow often clog a river by forming a barrier on it. Earthquakes are normally one of the main causes of rockfall, landslide and mudflow (Huang et al., 2008). The ancient barrier lake refers to the remains formed by such events a long time ago. Previous studies about the barrier lake mainly focused on the formation mechanism and stability of the barrier and the environment change with the life of the barrier. Weidinger (1998) investigated the stability of the landslide barriers located in the Himalayas. Trauth and Strecker (1999) dated the formation time of the landslide barrier lake located in northwestern Argentina. Wassmer et al. (2004) investigated the landslide barrier lake located in the Rhine Valley of Switzerland and the research was mainly focused on the failure mechanism of the barrier. Krivonogov (2005) studied the ice-dammed lake located in northern Mongolia and focused on the formation time of the barrier and the environment during the time when the lake existed. Moreiras (2006) investigated the approximate formation time of the landslide barrier lake located on the Cordon del Plata River of in the central Andes and he considered the clogging event related to seismicity, together with climatic conditions, rock formations and geological structures. Yang et al. (2005) investigated the evolution of the ancient barrier lake in the Diexi area by analysing the lithology and sediment system. An et al. (2008) considered that the lacustrine deposit of the ancient barrier lake along the Minjiang Fault reflects the tectonic activities of the fault. Zhang et al. (2009) investigated the climatic variation associated with the Diexi's ancient dammed lake by AMS (accelerator mass spectrometry)- ${ }^{14} \mathrm{C}$ dating and granulometry. They divided the evolution of the palaeoclimate in the research area into three stages: stage I (40.5-33.4 ka BP - before present) being cold and dry climate, stage II (33.4-31.7 ka BP) being warm and humid, and stage III (31.7-31.1 ka BP) being relatively warm and humid. Wang et al. (2000, 2005, 2007, 2009) studied the geological environment and climatic evolution by dating the deposits in 


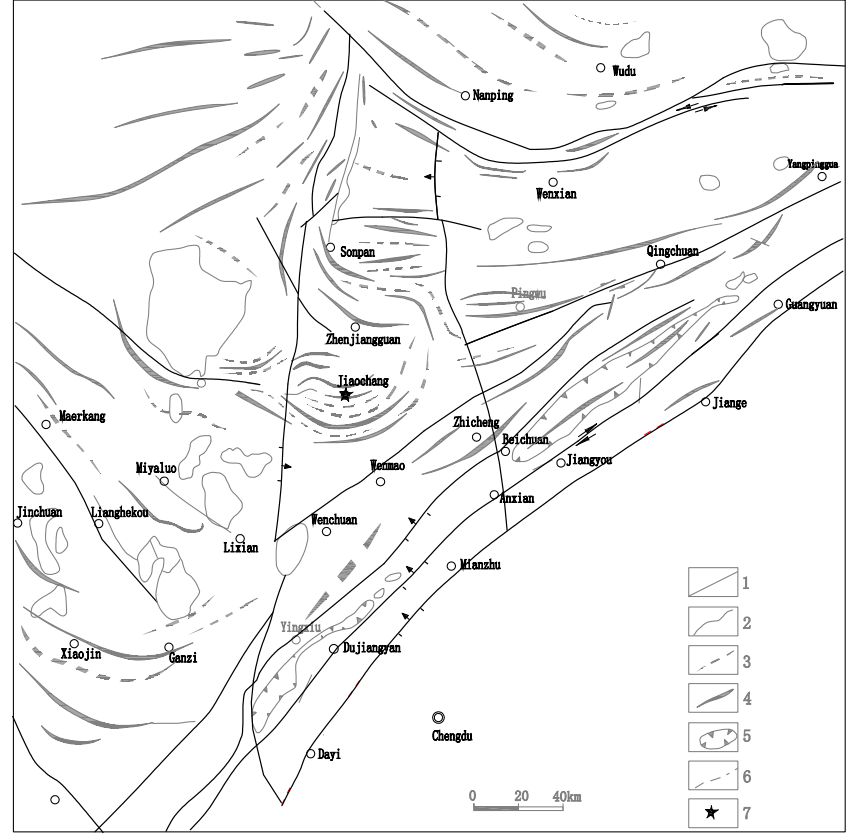

Figure 1. Regional geology.

the Diexi barrier lake and indicated that the barrier lake was formed about $30000 \mathrm{aBP}$ ago and disappeared about $15000 \mathrm{a}$ later with a climatic evolution sequence similar to what has been discovered by Zhang et al. (2009).

However, studies on the palaeoclimate and palaeoenvironment were carried out by taking barrier lake sediments to investigate the climate change law. Chen et al. (2000, 2003) investigated the palaeoenvironmental features of the Daihai barrier lake by taking core samples between 12.34 and $14.18 \mathrm{~m}$ in depth (age: $10.5 \mathrm{ka} \mathrm{BP}$ ). Wu et al. (2000) and Zhu et al. (2004) obtained a function between the total organic carbon and its isotope records in the Xingcuo Lake sediments and the corresponding precipitation and temperature. Zhao et al. (2007) investigated the ancient vegetation environment in the Ruoergai Basin with sporopollen analysis. By sampling from the outcrops, Duan (2002) and Duan et al. (2002) indicated that the palaeoclimate in the Diexi area experienced an evolution of drought-humectation-drought.

By testing the sediments in the Sant'Arcangelo Basin, Moretti et al. (2007) indicated that the formation of the inner deformation of the sediments was caused by earthquakes. Wang et al. $(2006,2011)$ attributed the wave-like structures of the sediments in the Diexi ancient barrier lake to earthquakes. Sims (1975) concluded that the wave-like structures of barrier-lake sediments may develop in the following cases: the lake being close to the active tectonic zone in the contemporary age; sediments being prone to liquefaction; the wavelike structure of the sediments being similar to the structures formed by the earthquake-vibration test; the deformational scale of the sediments being small and normally constrained

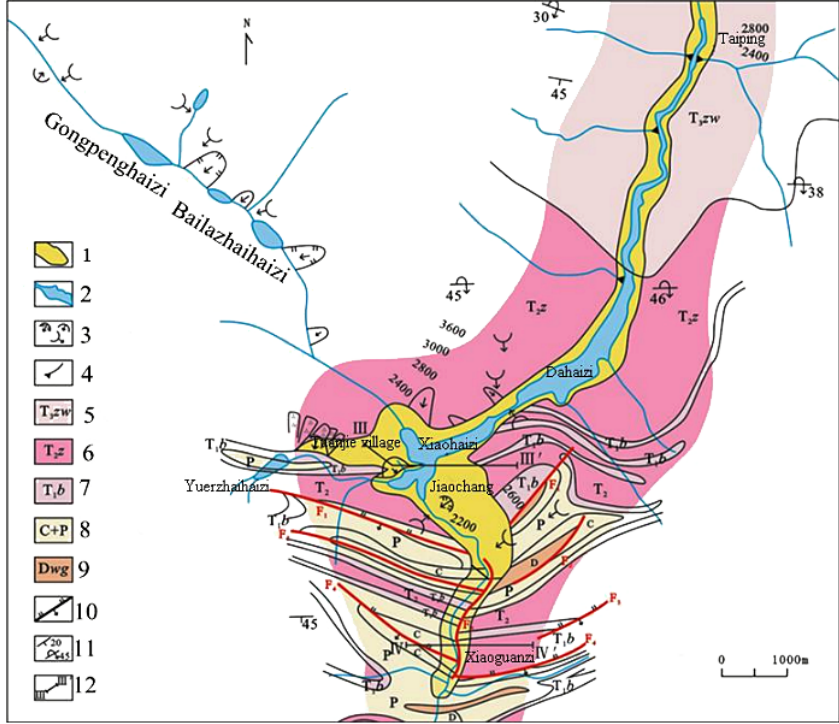

Figure 2. Geological map of the Diexi area.

by the lake boundaries; and the deformational structures being limited to a single stratum by relative horizontal layers.

As above, studies about the Diexi barrier lake so far mainly focused on the morphology of the sediments exposed and the environmental indicators in the sediments. However, researches on the correlation between the palaeoclimate and palaeoenvironment and the palaeoseismic events in this area are rarely found in literature. The present study takes the sediments of the ancient Diexi barrier lake to investigate the palaeoenvironment and palaeoseismic events. A core drilling and entire profile sampling was conducted at the centre of the Diexi barrier lake, near the Tuanjie and Jiaochang villages. The environmental information (sporopollen, carbon and oxygen isotope, organic matter, calcium carbonate, granularity) in the sediments were obtained. Based on this, $10 \mathrm{cli}-$ matic and environmental periods and 10 disturbance sections with wave-like structure along the drill hole are interpreted. It is found that there is a close correlation between the palaeoclimatic evolution and the palaeoseismic events.

\section{Geological background}

The research area is located in the northwestern Sichuan Plateau at the eastern edge of Tibetan Plateau formed by the crush and convergence of the Indian Plate and the Eurasian Plate. The region crosses the alpine valley region in the transition between the northwestern Sichuan Plate and the Sichuan Basin, where the well-known "north-south earthquake tectonic zone" is located. The region is surrounded by three tectonic plates: the Qinghai-Tibet Plate, the Yangzi Plate and the North China Plate. The action of the Indian Plate, the Pacific Plate and the Eurasian Plate makes the structure of this area complex. Revolving tectonic 


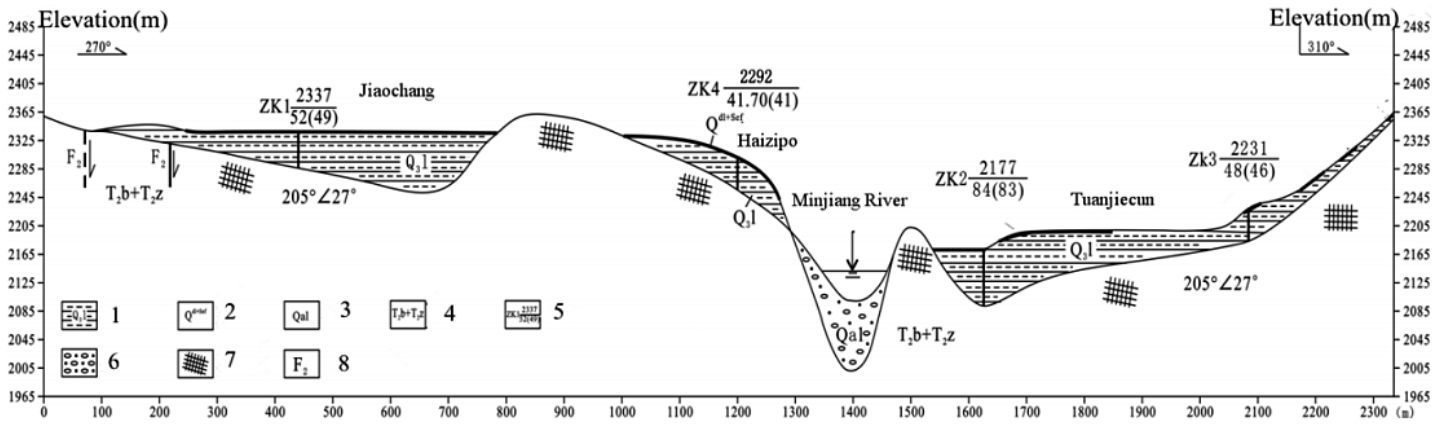

Figure 3. Typical cross section of the Diexi barrier lake (Section III-III' in Fig. 2.)

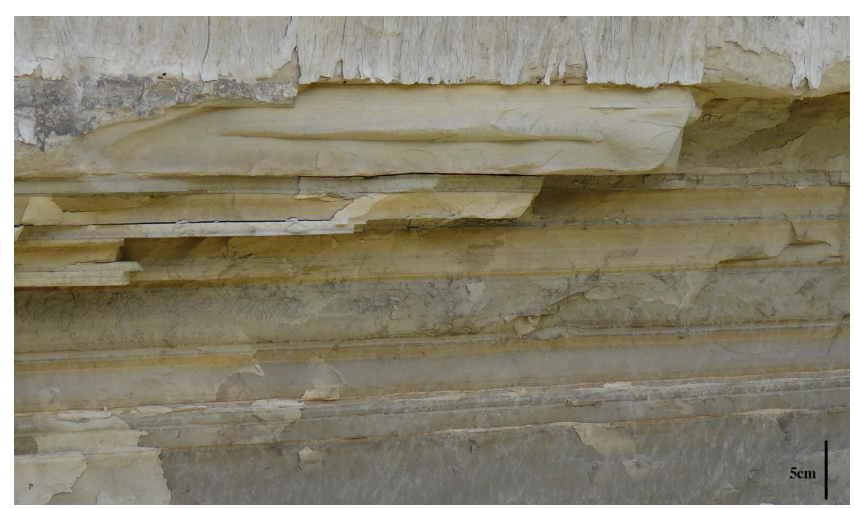

Figure 4. Structure of lacustrine sediment in the Diexi barrier lake.

systems are widely spread in the Minjiang River regions. The Jiaochang Formation with a mountain-shaped arcuate structure is of several hundred metres wide (Fig. 1).

The Diexi ancient barrier lake is located in the deep Vshaped gorge region of the Minjiang River (Fig. 2), where mountains are high, the gorge is deep and the river current is fast with an average water surface gradient of about $10.3 \%$. The thickness of the sediment in the middle of the barrier lake near the Tuanjie and Jiaochang villages is about $200 \mathrm{~m}$. The age of the sediments at the bottom is about $30000 \mathrm{a}$ and of those at the top about $15000 \mathrm{a}$.

The barrier dam was formed by a series of landslides that originated from the bank slopes. As shown in Fig. 3, the top elevation of the lake sediments is about $2340 \mathrm{~m}$ a.s.l. The thickness of the sediments near Tuanjie and Jiaochang villages is greater than $200 \mathrm{~m}$. In this area, the sediments are silty clay. At the tail of the barrier lake in Taiping Village (Fig. 2) the particle size is greater, showing a fluvial deposit feature. The sediments in the lake centre consist mainly of layered silty sands and clay with clear colour variation (Fig. 4). The thickness of the lamina is $2-5 \mathrm{~cm}$.

\section{Methodology}

Four drillings (ZK1, ZK2, ZK3 and ZK4) were carried out in the Jiaochang and Tuanjie area, the central part of the ancient Diexi barrier lake. The depth and top elevation of the four drill holes are 52, 84, 48 and $41.7 \mathrm{~m}$, and 2337, 2177, 2231 and $2292 \mathrm{~m}$ a.s.l., respectively. The drilling core, in total $216 \mathrm{~m}$ long, was well photographed and recorded. In order to obtain the environmental information recorded in the sediment, soil samples were taken at every $4 \mathrm{~m}$ from the core and in total 53 samples were collected. Each sample was divided into three parts for spore-pollen and organic-matter testing to extract the climatic information during the process of sediment deposition. In addition, 108 soil samples were taken from the core at every $2 \mathrm{~m}$. Each sample was divided into three parts for testing of carbon and oxygen isotopes, calcium carbonate and particle size distribution, respectively. A dating test was carried out on the core at the soleplate altitude and the top for determining the sediment formation and extinction times.

All tests were carried out according to Chinese standards as listed in the reference list. The sporopollen tests followed SY/T 5915-2000; the stable carbon and oxygen isotope tests were based on SY/T 5915-2000; organic matter tests were according to NY/T85-1988; soil carbonate was based on calcium carbonate tests NY/T86-1988; particle size distribution followed GB/T50123-1999; and dating tests were according to $\mathrm{AMS}-{ }^{14} \mathrm{C}$.

\section{Results}

\subsection{Palaeoclimatic indicators}

In total, 12532 sporopollens of 46 kinds are identified from the tests. The content distribution of sporopollen along the elevation is shown in Fig. 5. The arboreal sporopollen comprises the dominant content of about 59.9-89.1\% with an average of $76.2 \%$. Shrubby and herbaceous sporopollen is second with the content of $6.7-36.9 \%$ and average of $16.9 \%$. Ferny spores and algous sporopollen rank third with the content of $0.9-17.0 \%$ and average of $6.9 \%$. The arboreal 


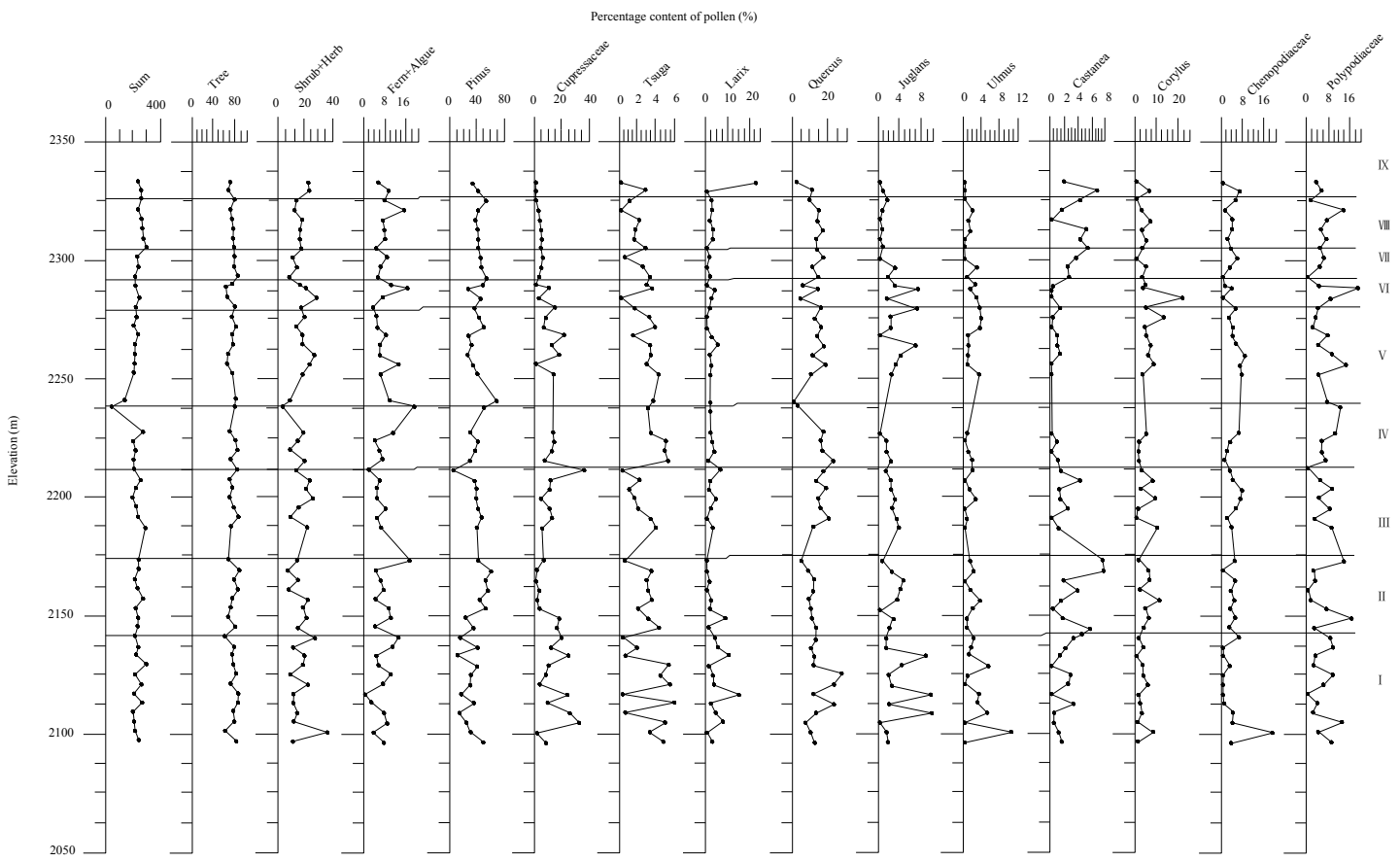

Figure 5. Pollen and spore schema with elevation.

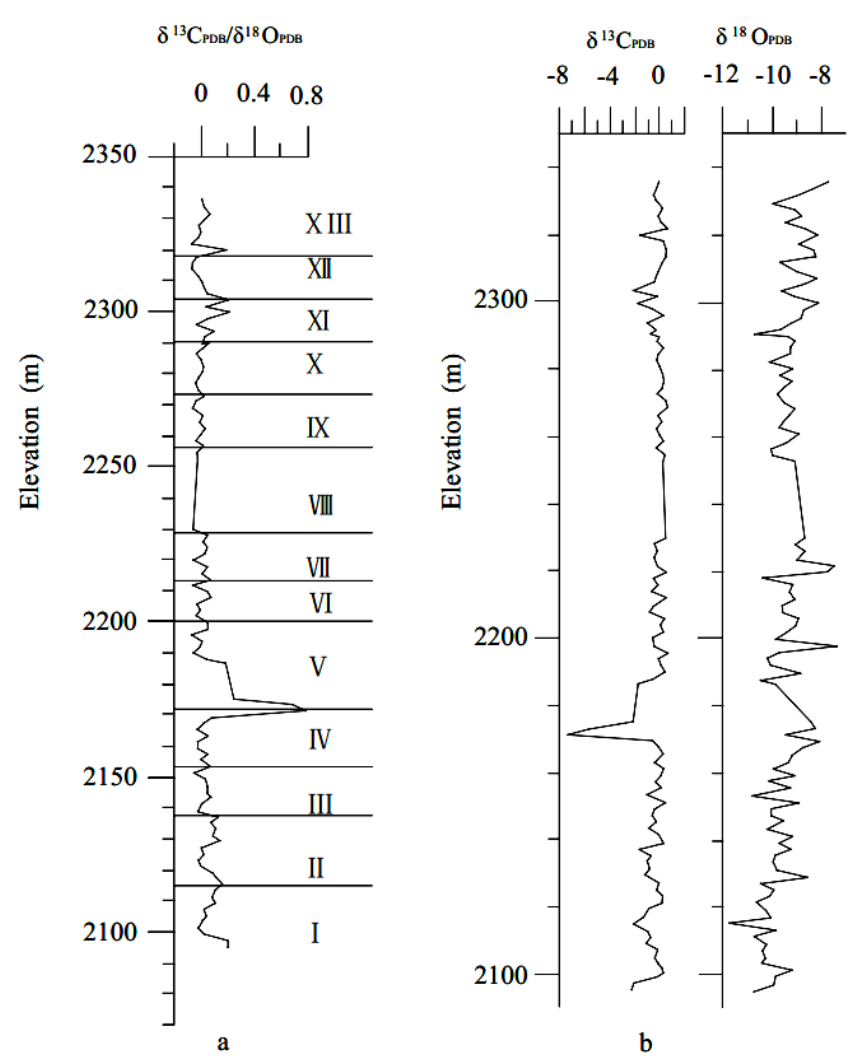

Figure 6. Carbon and oxygen isotopes: (a) ratio of $\delta^{13} \mathrm{C}$ to $\delta^{18} \mathrm{O}$; and (b) values of $\delta^{13} \mathrm{C}$ and $\delta^{18} \mathrm{O}$.

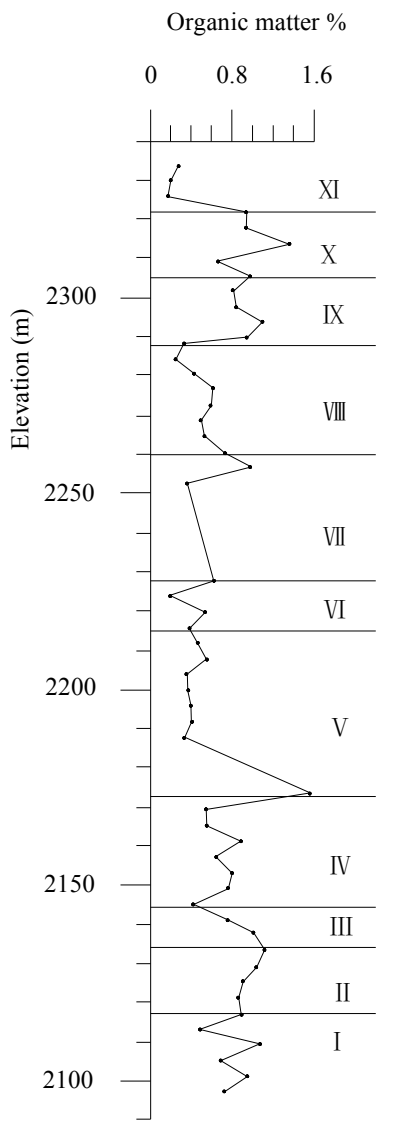

Figure 7. Average content of organic matter. 


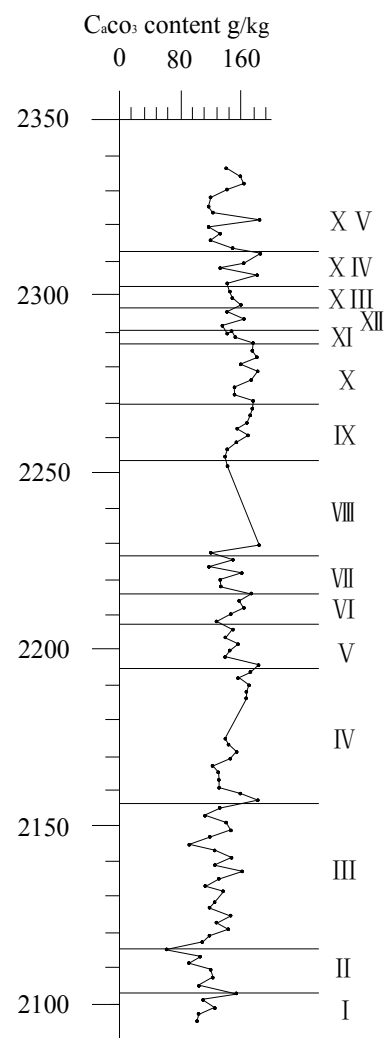

Figure 8. Content of $\mathrm{CaCO}_{3}$ with elevation.

pollens mainly include Pinus, Cupressaceae and Quercus with little PicealAbies, Tsuga, Ulmus, Betula, Juglans, Tilia and Carya. The shrubby and herbaceous pollens include Corylus, Ephedra, Ericaceae, Artemisia, Chenopodiaceae, Gramineae, Liliaceae and Cyperaceae. The ferny spore and algous pollens include Polypodiaceae and Concentricystis.

As shown in Fig. 6, the maximum value of $\delta^{13} \mathrm{C}$ is 0.66 and the minimum is -7.35 , with an average of -0.43 . The maximum value of $\delta^{18} \mathrm{O}$ is -7.44 and the minimum is -11.72 , with an average of -9.42 . The ratio of $\delta^{13} \mathrm{C}$ to $\delta^{18} \mathrm{O}$ ranges from 0.77 to -0.08 , with an average of 0.05 . It is noted in Fig. 6 that both $\delta^{13} \mathrm{C}$ and $\delta^{18} \mathrm{O}$ show the similar variation pattern along the elevation.

In the entire elevation profile, the maximum value of the organic matter content is $1.57 \%$ and the minimum is $0.17 \%$, with an average of $0.68 \%$ (Fig. 7). According to the variation of the content, the whole profile can be divided into 11 segments (segments I-XI). As shown in Fig. 8, the maximum content of the calcium carbonate $\left(\mathrm{CaCO}_{3}\right)$ is $187.04 \mathrm{~g} \mathrm{~kg}^{-1}$ and the minimum is $58.66 \mathrm{~g} \mathrm{~kg}^{-1}$, with an average of $141.49 \mathrm{~g} \mathrm{~kg}^{-1}$ in the entire elevation profile. According to the variation of the content of $\mathrm{CaCO}_{3}, 15$ segments can be identified along the elevation profile.

The mean particle size, $d_{50}$, is presented in Fig. 9 along the elevation. The maximum value of the mean particle size is $0.071 \mathrm{~mm}$ and the minimum is $0.002 \mathrm{~mm}$, with an average of

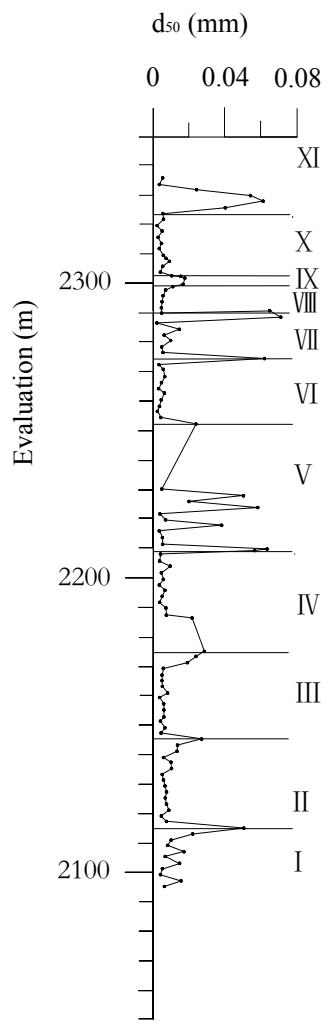

Figure 9. Mean particle size, $d_{50}$.

$0.013 \mathrm{~mm}$. The distinct variation of $d_{50}$ divides the elevation profile into 11 segments. Through the dating according to the method of AMS $-{ }^{14} \mathrm{C}$, the year at $2094 \mathrm{~m}$ a.s.l. is $30830 \mathrm{a} \mathrm{BP}$ and that at $2306 \mathrm{~m}$ is $16902 \mathrm{a} \mathrm{BP}$.

\subsection{Disturbance segments in the drilling core}

Through visual examination of the drilling core, 10 segments are identified as they show disturbance structures similar to those shown in Fig. 10. These disturbed segments typically have the following features: (1) wavy and wrapping structure is popular; (2) the laminas vary in thickness; and (3) the disturbed structure is sandwiched by the neighbouring upper and lower horizontal layers.

As shown in Fig. 11a, the wrapping structure is a kind of structure formed by the flow of seismic liquefaction under an unconsolidated condition (Sims, 1975). Fig. 11b presents a flame structure in a single layer, which is confined by horizontal stratification at the top, indicating a younger lacustrine deposit after the disturbance. This kind of disturbance exposed in the drilling core and outcrop is thought to be the product of earthquake vibrations, which liquefy the unsolidified lacustrine sedimentation. 

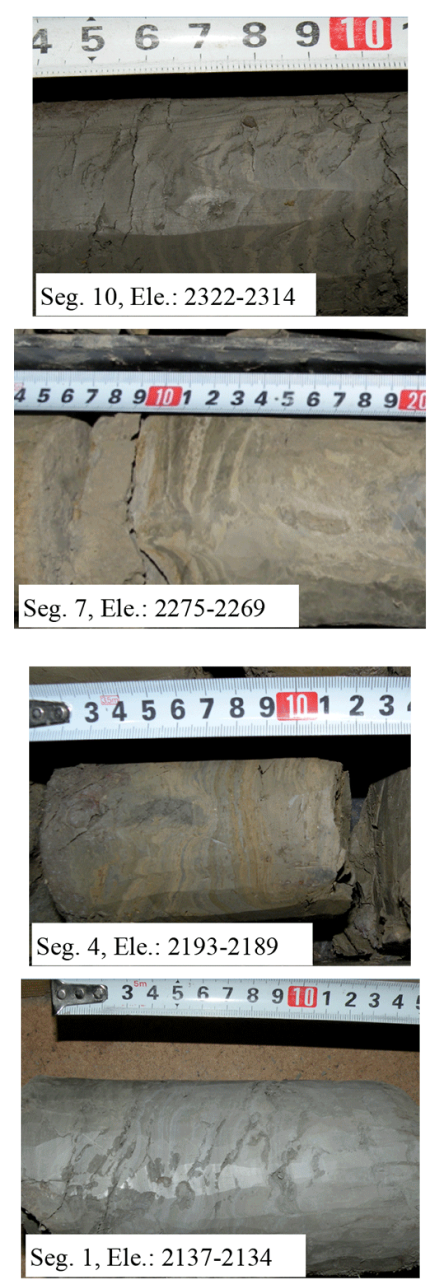
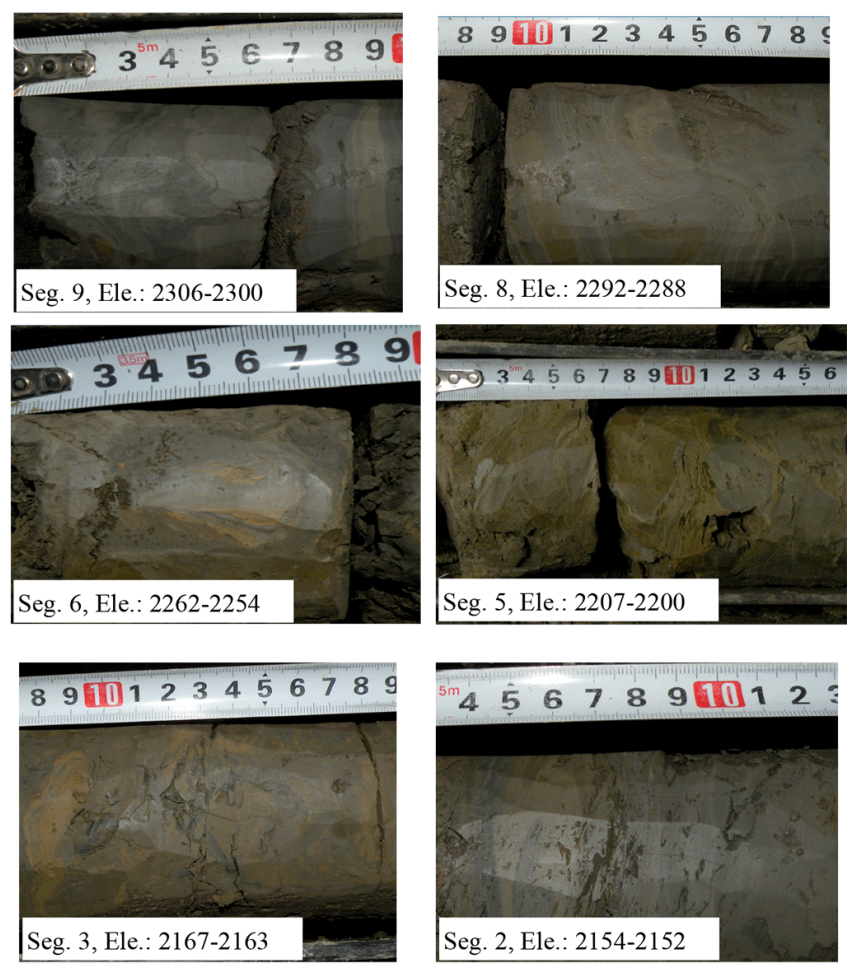

Seg: Segment

Ele: Elevation (m a.b.s.l.)

Figure 10. Features of disturbance layers in the drilling core.

\section{Discussion}

It is well known that the sporopollen is one of the palaeontology indicators which are used for climate proxies. Plants such as Pinus, Cupressaceae and Chenopodiaceae indicate chilliness and drought, while Tsuga, Quercus, Ulmus and Corylus plants indicate warmth and humectation. As shown in Fig. 5, arboreal sporopollen content is the most pronounced followed by shrubby and herbaceous sporopollen. The content of ferny spores and algous sporopollen is relatively low (in most case less than $10 \%$ ). According to the variation of sporopollen, the whole elevation profile can be divided into nine segments (I-IX) corresponding to nine climates. In each segment, Pinus sporopollen dominates, followed by Quercus or Cupressaceae.

Segment I presents a Pinus-Cupressaceae-QuercusChenopodiaceae sporopollen group. According to the average content of Pinus, Cupressaceae, Chenopodiaceae (indicating chilliness and drought), Quercus and Tsuga (indicating warmth and humectation), the climate in this segment would be cool and semi-humid and the vegetation represents an acerose and broadleaved-forest type.

Segment II is mainly a Pinus-Quercus-Chenopodiaceae sporopollen group. The contents of all sporopollen are relatively stable. Compared to Segment I, the content of Pinus and Corylus increased, that of Quercus and Larch obviously decreased, while that of Chenopodiaceae and Artemisia stay unchanged. This indicates a cold and dry climate and a vegetation of acerose-leaved-forest type.

Segment III presents a Pinus-Quercus-CupressaceaeChenopodiaceae sporopollen group. The content of Pinus obviously decreases, while that of Cupressaceae and Quercus increases sharply, as well as that of Larch. As Quercus indicates warmth and humectation, the climate in this segment is cool and of semi-dry and the vegetation is of the acerose and broadleaved-forest-grassland type.

Segment IV is mainly a Pinus-Quercus-CupressaceaeArtemisia sporopollen group. The content of Pinus and $\mathrm{Cu}-$ pressaceae is basically unchanged. The content of Larch and Chenopodiaceae obviously decreases, while that of Quercus 
Table 1. The palaeoclimatic periods in the study area.

\begin{tabular}{rlccll}
\hline Segment & Elevation of & \multicolumn{2}{c}{ Palaeoclimate and palaeoenvironment } & \\
& disturbance & Elevation & Period & & \\
& layer (a.s.1.) & (a.s.1.) & (a BP) & Climate & Vegetation \\
\hline 10 & $2321-2313$ & $2323-2333$ & $15650-14992$ & warm-humid & forest \\
9 & $2306-2300$ & $2301-2323$ & $16902-15650$ & warm-dry & forest-grassland \\
8 & $2291-2288$ & $2290-2301$ & $17413-16902$ & cool-dry & forest-grassland \\
7 & $2275-2269$ & $2273-2290$ & $18531-17413$ & cold-dry & forest-grassland \\
6 & $2262-2253$ & $2229-2273$ & $21425-18531$ & hot-dry & forest \\
5 & $2206-2200$ & $2207-2229$ & $22872-21425$ & warm-dry & forest \\
4 & $2193-2189$ & $2174-2207$ & $25043-22872$ & cold-dry & forest-grassland \\
3 & $2166-2163$ & $2146-2174$ & $26916-25043$ & cool-dry & forest-grassland \\
2 & $2154-2152$ & $2115-2146$ & $29077-26916$ & hot-humid & forest \\
1 & $2137-2134$ & $2095-2115$ & $30830-29077$ & warm-humid & forest \\
\hline
\end{tabular}
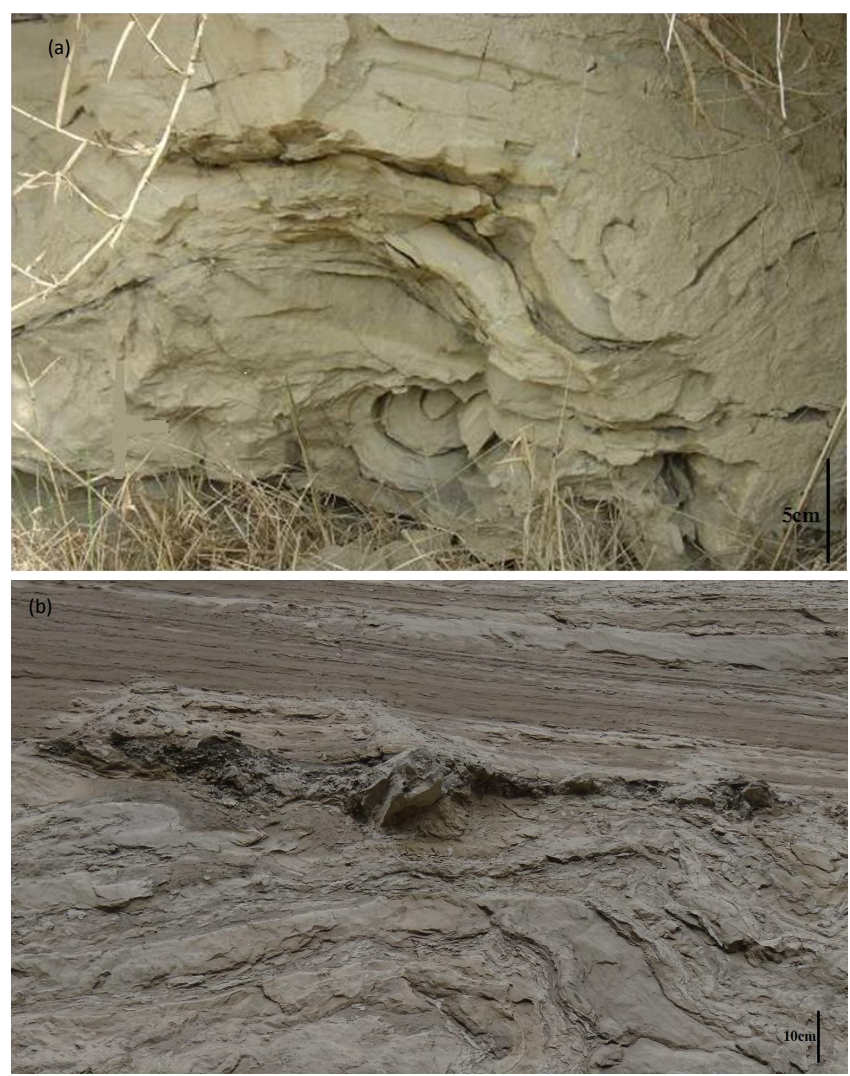

Figure 11. Earthquake-induced disturbance layer in the sediment exposed on an outcrop. and Tsuga increases markedly. This indicates the climate in this segment is of warm and humid features with acerose and broadleaved-forest-grassland vegetation.

Segment V is mainly a Pinus-Quercus-CupressaceaeChenopodiaceae sporopollen group. The content of Larch and Gramineae increases slightly. The content of Quercus and Tsuga decreases. This indicates a cold and semi-dry climate with vegetation of the acerose and broadleavedforest type.

Segment VI is a Pinus-Quercus-Corylus-Artemisia sporopollen group. The content of Pinus and Cupressaceae increases, while that of Chenopodiaceae, Quercus and Tsuga decreases markedly. This indicates a climate of warm and humid features with vegetation of the acerose-leavedforest type.

Segment VII is a Pinus-Quercus-Chenopodiaceae sporopollen group. The content of Pinus increases, while that of Quercus increases, indicating a cold and semi-humid climate with vegetation of the forest-grassland type.

Segment VIII is a Pinus-Quercus-Cupressaceae-CorylusGramineae sporopollen group. The content of Pinus decreases, while that of Quercus increases, indicating a climate of cool and mid-drought features with vegetation of the acerose and broadleaved-forest-grassland type.

Segment IX is mainly a Pinus-Quercus-CorylusChenopodiaceae sporopollen group. The content of Pinus slightly increases, while that of Quercus obviously decreases, indicating a cold and dry climate with forest-type vegetation .

The climates in the above-mentioned nine segments exhibit alternate warm-humid and cold-dry climates and alternate vegetation types (forest-grassland type in segments III, IV, VII and VIII and forest type in segments I, II, V, VI and IX).

Referring to the study by Chen et al. (2000) on open freshwater lakes, we consider that the high value of $\delta^{13} \mathrm{C}$ indicates warm climate, while the low value of $\delta^{13} \mathrm{C}$ means cold climate. However, the high value of $\delta^{18} \mathrm{O}$ indicates cold 


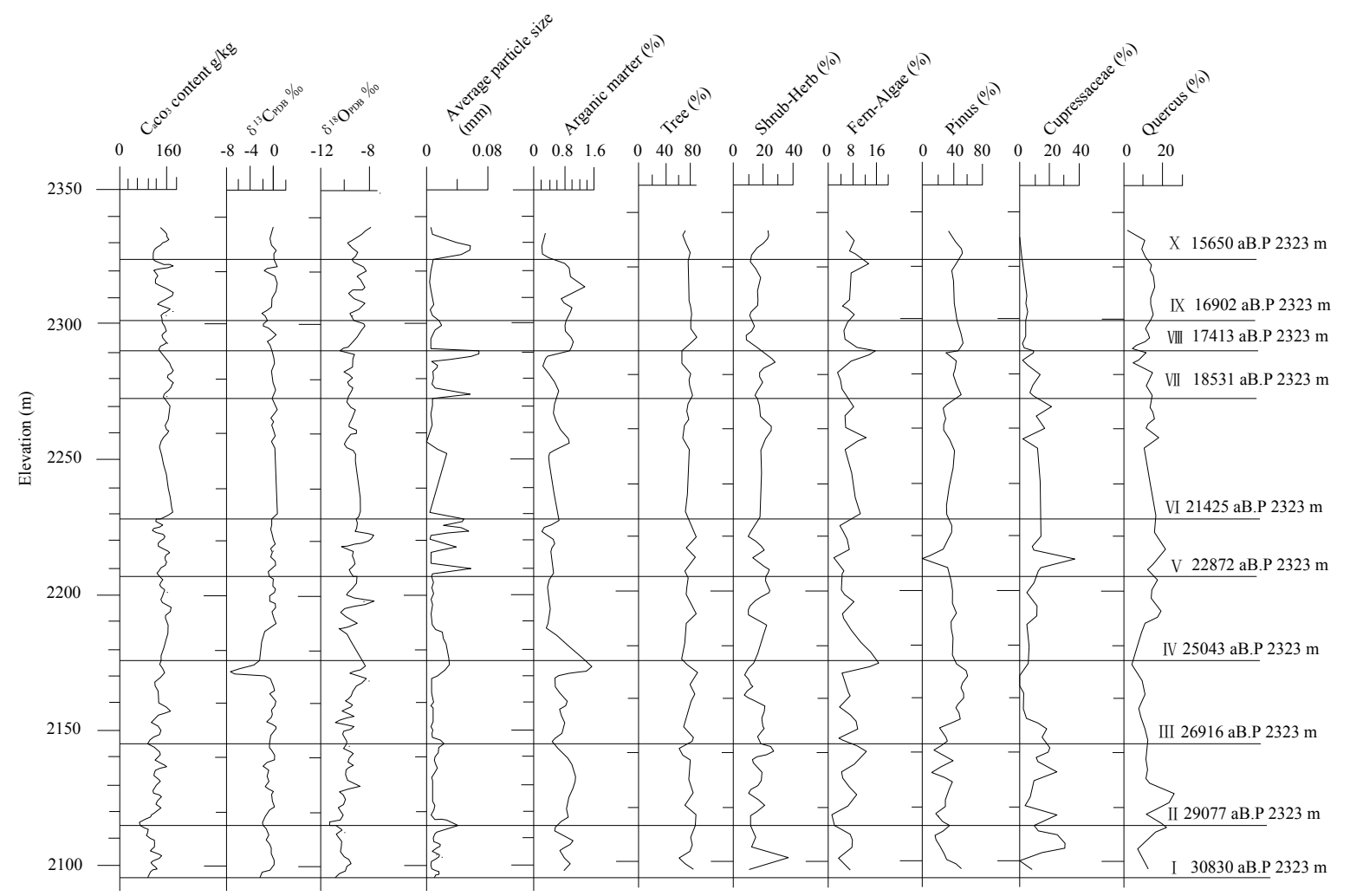

Figure 12. Delineation of palaeoclimate in the study area.

climate, while the low value means humid climate. As shown in Fig. 6, the values of $\delta^{13} \mathrm{C}$ and $\delta^{18} \mathrm{O}$ and their ratio fluctuate with elevation. According to the variation feature of $\delta^{13} \mathrm{C} / \delta^{18} \mathrm{O}$, the entire elevation profile is differentiated into 13 segments, each representing a climate type. Segments I, II, III and X indicate humid climate and others are dry. Additionally, segments I, II, IV and V reflect typical cold climates. In general, the upper part of the profile experienced somewhat warm and dry climates, while the lower part experienced relatively cold and humid climates.

The organic matter represents the enrichment of humus in soils, which is generally caused by bioorganic actions. The high percentage of the organic matter not only illustrates the accumulation of the humus, but also indicates a humid condition during the formation of soil and an active process of bioorganic action. A warm and humid climate favours luxuriant growth of vegetation, which is beneficial to the accumulation of humus. Although the content of the organic matter in the stratum would be affected by the decomposition of the organic matter itself, the content measured today still reflects the biomass values at that time. According to the variation of organic matter content in Fig. 7, the elevation profile can be differentiated into 11 segments.

Based on studies on contemporary lakes, Wang and Li (1991) indicated that a close relationship exists between the sedimentation of calcium carbonate and the climate and environment, as the content of calcium carbonate in the sediments reflects the palaeoclimatic features in the process of forming sediments. Generally, the high $\mathrm{CaCO}_{3}$ content represents a cold and dry climate, while the low represents a humid climate. According to this variation of $\mathrm{CaCO}_{3}$ content in Fig. 8, the elevation profile can be differentiated into 15 segments. Segments I and II are relatively warm and humid, while segments IX, X and XIV are somewhat cold and dry.

The Diexi barrier lake is an open and drained lake and its sediments stem from materials upstream of the Minjiang River. The granularity test indicates that the sediments are mostly silty clay, clayey silt and sandy silt. The coarse grain represents plentiful rainfall, humid climate and strong hydrodynamic conditions, while the finest grains represent less rainfall, dry climate and weak hydrodynamic conditions (Chen et al., 2003). As shown in Fig. 9, the average particle sizes exhibit strong fluctuation with elevation. The variation in the lower portion of the profile is relatively small, while that in the upper portion is relatively large. According to the granularity, the entire profile can be differentiated into 11 segments. Segments I, V, VII, IX and XI indicate a relatively humid climate, while segments II, III, IV, VI VIII and $\mathrm{X}$ are relatively dry.

By combining the above-mentioned individual climatic indicators and the dating results, Fig. 12 and Table 1 are obtained to summarize and delineate the palaeoclimatic history 
in the Diexi area. In total, 10 climate and environment segments are identified. From about 30830 till 26916 a BP, the Diexi area was covered by forest vegetation and the climate changed from warm-humid to hot-humid. Since 26916 a BP, the temperature became lower and the vegetation was of forest-grassland type. From about 22872 a BP, the climate changed to be warm-dry and hot-dry with forest vegetation in this area. After that a cold climate came and lasted for about 1600 a (from 18531 to $16902 \mathrm{a} \mathrm{BP}$ ) and the vegetation was forest-grassland type. From 16902 to 14992 a BP the temperature increased. The whole profile shows a cyclic evolution of climate from warm-humid to cold-dry.

Comparing the palaeoclimate segments in Fig. 12 and Table 1 and the disturbance zones in Fig. 10, there is a good correlation between the climatic and environmental changes and the earthquake events. It is inferred that a strong earthquake is usually accompanied by climate change. In other words, the atmosphere the climate relies on and the rock cycle the earthquake action relies on are closely associated. Based on the preliminary results from this study, we considering that the climate change and the geological and environmental evolution of the eastern edge of Tibetan Plateau may proceed cyclically at an interval of about $15000 \mathrm{a}$, and that climate change was accompanied by seismic events. To expand on this argument, further study is required to decipher the inner correlations between the climate change and earthquake events.

\section{Conclusions}

The present study focuses on the Diexi barrier lake in the Minjiang River, which is located in a complex geological region. Drilling and sampling were conducted in the centre of the barrier lake. Climatic indicators were examined through an elevation profile from $2090 \mathrm{~m}$ to $2330 \mathrm{~m}$ a.s.l. to recover the palaeoclimate in this area. Based on the foregoing discussion, the main conclusions are as follows:

1. Ten climatic periods have been identified for the Diexi barrier lake area within the time span from 30000 to 15000 a BP, based on examination of the climatic indicators, such as spore-pollen, organic matter, carbon and oxygen isotopes, calcium carbonate and particle size.

2. Ten earthquake-induced disturbance layers in the lake sediments were identified through examination of the drilling core. This indicates that from 30000 to $15000 \mathrm{a} \mathrm{BP}$, there were at least 10 strong earthquakes in the Diexi area.

3. The disturbance sections formed by earthquakes show good consistency with the climate changes, indicating that the geologic evolution and the climatic and environmental changes are associated.
Acknowledgements. This study is supported by the National Natural Science Foundation of China (no. 41072230 and 51309176) and funding from the State Key Laboratory of Geohazard Prevention and Geoenvironment Protection (SKLGP2012Z008).

Edited by: R. Lasaponara

Reviewed by: two anonymous referees

\section{References}

An, W., Zhao, J. Q., and Yan, X. B.: Tectonic deformation of lacustrine sediments in Qiangyang on the Minjiang fault zone and ancient earthquake, Seismol. Geol., 4, 980-988, 2008.

Chen, J. A., Wan, G. J., and Tang, D. G.: Modern climate change Erhai Lake sediment grain size and isotopic records, Nat. Sci. Prog., 10, 253-259, 2000.

Chen, J. A., Wan, G. J., and Zhang, F.: Environmental record in lake sediments at different time scales - a case study in sediment grain size, Chinese Sci. Ser. D, 33, 563-568, 2003.

Duan, L. P.: The Ancient Barrier Lake and Geoenvironment, Diexi, Minjiang River, Ph.D. thesis, Chengdu University of Technology, China, 2002.

Duan, L. P., Wang, L. S., and Yang, L. Z.: The ancient climatic evolution characteristic reflected by carbon and oxygen isotopes of carbonate in the ancient barrier lacustrine deposits, Diexi, Minjiang River, The Chinese J. Geol. Hazard Control, 13, 91-96, 2002.

Krivonogov, S. K., Sheinkman, V. S., and Mistruykov, A. A.: Stages in the development of the Darhad dammed lake (Northern Mongolia) during the Late Pleistocene and Holocene, Quaternary Int., 136, 83-94, 2005.

Moreiras, S. M.: Chronology of a probable geotectonic Pleistocene rock avalanche, Cordon del Plata (Central Andes), Mendoza, Argentina, Quaternary Int., 148, 138-148, 2006.

Trauth, M. H. and Strecker, M. R.: Formation of landslide-dammed lakes during a wet period between 40,000 and $25,000 \mathrm{yr}$ B. P. in northwestern Argentina, Palaeogeogr. Palaeocl., 153, 277-287, 1999.

Wang, L. S., Yang, L. Z., and Li, T. B.: Evolution mechanism of Jiaochang earthquake landslide on Minjiang River and it s cont rolling, J. Geol. Hazards Environ. Preserv., 11, 195-199, 2000.

Wang, L. S., Yang, L. Z., and Wang, X. Q.: Discovery of huge ancient dammed lake on upst ream of Minjiang River in Sichuan, China, J. Chengdu University of Technology: Science and Technology Edition, 32, 1-11, 2005.

Wang, L. S., Wang, X. Q., and Xu, X. N.: What happened on the upstream of Minjiang River in Sichuan Province 20,000 years ago, Earth Sci. Front., 14, 189-196, 2007.

Wang, P., Zhang, B., Qiu, W. L., and Wang, J. C.: Soft-sediment deformation structures from the Diexi paleo-dammed lakes In the upperreaches of the Minjiang River, east Tibet, J. Asian Earth Sci., 40, 865-872, 2011.

Wang, S. B., Li, Y., and Xia, X. G.: Magnetostratigraphic Study of Lake Sediments in Jiaochang, Maoxian County, Sichuan, 426 pp., 2006.

Wang, S. M. and Li, J. R.: Lake sediments - effective means to study the history of climate - an example from Qinghai Lake and Daihai Lake, Chinese Sci. Bull., 36, 54-56, 1991. 
Wang, X. Q.: The Environment Geological Information in the Sediments of Diexi Ancient Dammed Lake on the upstream of Mingjiang River in Sichuan Province, China, Ph.D. thesis, Chengdu University of Technology, Chengdu, China, 2009.

Wassmer, P., Schneider, J. L., Pollet, N., and Schmitter-Voirin, C.: Effects of the internal structure of a rock-avalanche dam on the drainage mechanism of its impoundment, Flims sturzstrom and Ilanz paleo-lake, Swiss Alps, Geomorphology, 61, 3-17, 2004.

Weidinger, J. T.: Case history and hazard analysis of two lakedamming landslides in the Himalayas, J. Asian Earth Sci., 16, 323-331, 1998.

Wu, J. L., Li, S. J., and Wang, S. M.: Modern climatic signals recorded in Xincuo Lake sediments in Zoige Basin, eastern Tibetan plateau, China, J. Lake Sci., 12, 291-296, 2000.
Yang, W. G.: Research of sedimentary record in terraces and climate vary in the upper reaches of Mingjiang River, china, Ph.D. thesis, Chengdu University of Technology, Chengdu, China, 2005.

Zhang, Y., Zhu, L., and Yang, W., Luo, H., He, D., and Liu, J.: High resolution rapid climate change records of lacustrine deposits of Diexi Basin in the eastern margin of Qinghai-Tibet Plateau, 4030 ka BP, Earth Sci. Front., 5, 91-98, 2009.

Zhao, X. T., Qu, Y. X., and Zhang, Y. S.: Discovery of Shigu Paleolake in the Lijiang area, northwestern Yunnan, China and its significance for the development of the modern Jinsha River valley, Geol. Bull. China, 8, 960-969, 2007.

Zhu, D. G., Meng, X. G., and Zhao, X. T.: Lake-level change of Namco Tibet since the Late Pleistocene and environment information of clay minerals in lacustrine deposits, J. Geomechan., 10, 300-309, 2004. 